\title{
Effects of an onion by-product on bioactivity and safety markers in healthy rats
}

\author{
Eduvigis Roldán-Marín ${ }^{1,3}$, Britta N. Krath ${ }^{1,2}$, Morten Poulsen ${ }^{1}$, Mona-Lise Binderup ${ }^{1}$, Tom H. Nielsen ${ }^{4}$, \\ Max Hansen ${ }^{1}$, Thaer Barri ${ }^{2}$, Søren Langkilde ${ }^{1}$, M. Pilar Cano ${ }^{3}$, Concepción Sánchez-Moreno ${ }^{3}$ \\ and Lars O. Dragsted ${ }^{2 *}$ \\ ${ }^{1}$ Department of Toxicology and Risk Assessment, National Food Institute, Technical University of Denmark, Mørkhøj Bygade 19, \\ 2860 Søborg, Denmark \\ ${ }^{2}$ Department of Human Nutrition, University of Copenhagen, 30 Rolighedsvej, 1958 Frederiksberg, Denmark \\ ${ }^{3}$ Department of Plant Foods Science and Technology, Instituto del Frío, Consejo Superior de Investigaciones Científicas (CSIC), \\ José Antonio Novais 10, Ciudad Universitaria, E-28040 Madrid, Spain \\ ${ }^{4}$ Department of Plant Biology and Biotechnology, University of Copenhagen, 40 Thorvaldsensvej, 1871 Frederiksberg, Denmark
}

(Received 10 November 2008 - Revised 18 May 2009 - Accepted 26 May 2009 - First published online 17 August 2009)

\begin{abstract}
Onions are excellent sources of bioactive compounds including fructo-oligosaccharides (FOS) and polyphenols. An onion by-product was characterised in order to be developed as a potentially bioactive food ingredient. Our main aim was to investigate whether the potential health and safety effects of this onion by-product were shared by either of two derived fractions, an extract containing the onion FOS and polyphenols and a residue fraction containing mainly cell wall materials. We report here on the effects of feeding these products on markers of potential toxicity, protective enzymes and gut environment in healthy rats. Rats were fed during 4 weeks with a diet containing the products or a control feed balanced in carbohydrate. The onion by-product and the extract caused anaemia as expected in rodents for Allium products. No other toxicity was observed, including genotoxicity. Glutathione reductase (GR) and glutathione peroxidase (GPx1) activities in erythrocytes increased when rats were fed with the onion extract. Hepatic gene expression of $G r, G p x l$, catalase, 5-aminolevulinate synthase and NAD(P)H:quinone oxidoreductase was not altered in any group of the onion fed rats. By contrast, $\gamma$-glutamate cysteine ligase catalytic subunit gene expression was upregulated but only in rats given the onion residue. The onion by-products as well as the soluble and insoluble fractions had prebiotic effects as evidenced by decreased $\mathrm{pH}$, increased butyrate production and altered gut microbiota enzyme activities. In conclusion, the onion by-products have no in vivo genotoxicity, may support in vivo antioxidative defence and alter the functionality of the rat gut microbiota.
\end{abstract}

Onion by-products: Fructo-oligosaccharides: Hb: DNA damage: Antioxidant enzymes: Gene expression: Gut health

Fruits and vegetables are excellent sources of fibres, vitamins and minerals, but they also contain components like polyphenols, terpenes and alkaloids that may provide substantial health benefits beyond basic nutrition ${ }^{(1)}$.

The Allium genus includes approximately 500 species. Commonly used Allium vegetables include onion, garlic, leeks, chives and scallions, which are used all over the world $^{(2)}$. It has been shown that Allium species may help to prevent tumour promotion, CVD and ageing; all processes that are associated with free radicals ${ }^{(3)}$. Onions are regularly consumed forming part of the basic diet of many subjects. They have been recognised as an important source of valuable phytonutrients, such as flavonoids, fructo-oligosaccharides (FOS), thiosulphinates and other sulphur compounds ${ }^{(4)}$. These compounds have been implicated in providing health-promoting as well as adverse attributes to onions.
Other interesting biological onion properties reported are potential antioxidant, anticarcinogenic, antimutagenic, anti-asthmatic, immunomodulatory, antimicrobial and prebiotic characteristics ${ }^{(5)}$.

The constant increase in onion consumption and production in many countries has triggered a worldwide disposal of onion wastes in large amounts. Onion wastes could be processed and stabilised in order to obtain useful onion by-products for the food industry. Several onion by-products were characterised in a previous study as potential functional food ingredients with antioxidant and antibrowning properties ${ }^{(6)}$. An onion powder could be easily added into many foods to improve these technological properties, while also adding prebiotic or other health-related effects ${ }^{(7)}$.

Onion flavonoids, particularly the flavonol, quercetin and its glycosides, have been the target of a wide range of

Abbreviations: BGL, $\beta$-glucosidase; FOS, fructo-oligosaccharides; Gclc, $\gamma$-glutamate cysteine ligase catalytic subunit; GPx1, glutathione peroxidase; GR, glutathione reductase; GSH, glutathione; GUS, $\beta$-glucuronidase; OSC, organosulphur compounds.

* Corresponding author: Lars O. Dragsted, fax +45 353324 69, email 1dra@life.ku.dk 
in vitro and in vivo investigations, including actions on redox homeostasis $^{(8-12)}$. Organosulphur compounds (OSC) are also becoming target of many investigations due to their potential chemopreventive and antioxidant effects, but their toxic properties in animals and birds are also a cause of concern and limit the usefulness of onion wastes as animal feeds ${ }^{(13-15)}$.

Few, if any, in vivo studies have been done focusing on the fibre fractions in onions such as FOS. Onions have characteristic high contents of certain dietary fibres, particularly fructans and $\operatorname{FOS}^{(16-19)}$, but their chain length distribution differs from most other sources such as chicory. Inulin-type fructans have a potential role in colorectal cancer prevention, associated with their 'bifidogenic' prebiotic effect in animal models ${ }^{(20)}$. The use of FOS as food ingredients has triggered much research on their possible health effects. Functionally, they are used as non-digestible dietary fibre and technologically they are used for their texturing properties in many foodstuffs $^{(21)}$. Recently, other interesting uses of FOS have been described, including their use as sweeteners for diabetics ${ }^{(22)}$.

To the present knowledge, no studies have investigated the potential antioxidant and prebiotic in vivo effect of onion or onion by-products as FOS sources. Effects of onion components on gut health parameters including changes in $\mathrm{pH}$, transit time, bacterial activities and SCFA production need to be investigated. Previous studies with onions have provided evidence for some adverse effects on $\mathrm{Hb}$ biosynthesis and anaemia due to the formation of Heinz bodies in birds and some animal species, including rodents. The effects seem to be caused by some of the sulphur compounds, but details of the mechanism are lacking. As a consequence, haeme and redox homeostasis might be affected, and we therefore determined hepatic gene expression of the rate-limiting gene in haeme biosynthesis along with expression of several antioxidant enzymes.

We present here a rat model study aimed to evaluate the potential effect of an onion by-product and two derived onion fractions, a soluble onion extract rich in FOS and polyphenols and an onion residue fraction, on selected effects related to onion-containing compounds, including anaemia, antioxidant defence, phase 2 enzyme induction, gut health and related gene expression.

\section{Materials and methods}

\section{Chemicals}

All chemical reagents used are analytical grade from Fluka (Steinheim, Germany), Merck (Darmstadt, Germany) and Sigma-Aldrich (Steinheim, Germany). Ethanol (96\%) was purchased from De Danske Spritfabrikker (Aalborg, Denmark). Water is MilliQ (Millipore, Bedford, MA, USA) with $>18 \mathrm{M} \Omega$ resistivity.

\section{Dietary substances}

Onion powder was freeze-dried from an onion paste ${ }^{(6)}$ at Instituto del Frío-CSIC in Madrid. The onion paste was a 'Recas' cultivar onion by-product that was pasteurised before shipment. It was kept at $4{ }^{\circ} \mathrm{C}$ until the preparation of animal diets. In addition, two onion fractions were produced from the onion powder; an onion extract rich in FOS (water/ethanol soluble) and an onion residue (dry residue). They were produced at the National Food Institute, Technical University of Denmark as described later.

\section{Fructan and fructo-oligosaccharides extraction}

Fructans and FOS extraction from the onion powder was carried out following the modified Shiomi method with minor modifications described by Jaime et al. ${ }^{(23)}$. The total amount of onion powder used was $1.5 \mathrm{~kg}$. The yield of this powder was $60 \%$ onion extract rich in FOS and percentage of onion residue. The procedure used was the following: portions of $200 \mathrm{~g}$ freeze-dried, finely milled material was homogenised in 1 litre of $70 \%$ ethanol and immediately heated to the boiling point for $10 \mathrm{~min}$. Subsequently, the mixture obtained was centrifuged at $2930 \mathrm{~g}$ for $15 \mathrm{~min}$ at room temperature. The supernatant was decanted and the pellet was extracted one more time with $40 \mathrm{ml}$ of $70 \%$ boiling ethanol and centrifuged again after cooling. Supernatants were pooled and vacuum evaporated at $30-33^{\circ} \mathrm{C}$ to dryness obtaining an ethanolic extract. Pellets were combined as a residue fraction and lyophilised. The residue fraction contained $30 \%$ by weight of the starting material.

\section{Analysis for sugars, starch, fructo-oligosaccharides and quercetin in the onion fractions}

Samples were extracted at $80^{\circ} \mathrm{C}$ with $80 \%$ (v/v) ethanol, $20 \%$ $(\mathrm{v} / \mathrm{v})$ ethanol and finally water. The combined extracts were lyophilised and redissolved in water. Soluble sugars were determined by standard methods ${ }^{(24-26)}$. Starch was degraded to glucose units as previously described ${ }^{(27)}$ and fructans were determined after fructanase treatment according to the protocol of the manufacturer (Megazyme Intl., Bray, Ireland) All assays were performed in microplates using a Spectra-Max 190 microplate reader (Molecular Devices, Sunnyvale, CA, USA). High-performance anion exchange chromatographic analysis of fructo-oligosaccharide size distribution was performed as described for glucans ${ }^{(28)}$. For analysis of quercetin, each fraction was extracted twice with $96 \%$ ethanol, $70 \%$ ethanol, methanol and water, successively. The extracts were combined and concentrated by evaporation, added with genistein as an internal standard and analysed on a $2.1 \mathrm{~mm} \times 10 \mathrm{~cm}$ $\mathrm{C}_{18} \mathrm{BEH}$ column (1.7 $\mu \mathrm{m}$ particle size), using a UPLC-TQD system (Waters, Milford, MA, USA) operated in the multiple reaction mode. A gradient from 10 to $100 \%$ acetonitrilemethanol (1:1) with $0.1 \%$ formic acid with $0.7 \mathrm{ml} / \mathrm{min}$ flow rate was used, and quantification multiple reaction mode transitions for quercetin and genistein were $301>151$ and $269>133$, respectively. Analysis of each fraction was performed with and without preceding hydrolysis of glucosides in $1.2 \mathrm{M} \mathrm{HCl}$ at $90^{\circ} \mathrm{C}$ for $2 \mathrm{~h}$.

\section{Animals}

Thirty-two male Fisher 344 rats were obtained from Charles River (Sulzfeld, Germany). The animals were housed $2 \times 2$ in Macrolon cages with stainless steel wire lids. During the study the animals were maintained on a $12 \mathrm{~h}$ light and $12 \mathrm{~h}$ dark cycle at an average temperature and relative humidity of $22 \pm 1{ }^{\circ} \mathrm{C}$ and $55 \pm 5 \%$, respectively, and air was changed 
8-10 times/h. Diets and tap water were provided ad libitum. Animals were divided into four groups of eight rats with equal mean body weights. After $12 \mathrm{~d}$ of adaptation to the control diet, the rats were fed either (1) control diet; (2) control diet added $10 \%$ of onion by-product powder; (3) control diet added $7 \%$ of onion extract or (4) control diet added $3 \%$ onion residue for a period of 4 weeks until euthanisation (Table 1). Every diet was based on a purified rodent diet produced at the National Food Institute, Technical University of Denmark, according to Table 1. Animal experiments were carried out under the supervision of the Danish National Agency for the Protection of Experimental Animals. All animal study procedures have been approved by the Institutional Committee for Animal Experimentation, and the Institute has been approved for this type of experiment with rodents by the Danish Ministry of Justice.

\section{Transit time measurement}

One week before sacrifice, the rats were dosed with $5 \%$ of carmine solution. Each animal was dosed with $0.7 \mathrm{ml} / 100 \mathrm{~g}$ body weight. At dosing, the time, animal number and animal weight were recorded. One piece of faeces was collected from each cage once before dosing. After dosing, faeces were examined every hour for the appearance of red colour. At the time red faeces were observed, time was recorded and faeces collected in a tube. Afterwards, $30 \mathrm{mg}$ of the red faeces were suspended in $3 \mathrm{ml} 0 \cdot 1 \mathrm{M} \mathrm{NaOH}$, centrifuged at $2000 \mathrm{~g}$ for $30 \mathrm{~min}$, and absorbance was read at 450 and $550 \mathrm{~nm}$.

\section{Sacrifice and sampling}

After 4 weeks on the experimental diets, the animals were fasted overnight. The next day, after recording the body weight, the rats were anaesthetised in $\mathrm{CO}_{2} / \mathrm{O}_{2}$ and sacrificed by decapitation. Immediately after the decapitation, samples of blood were collected as detailed later. The liver was removed, weighed and grinded in liquid $\mathrm{N}_{2}$ to a fine powder. Three portions of $30 \mathrm{mg}$ each were stored separately for later analysis of antioxidant enzyme activities, gene expression and comet assay. The caecum was washed in ice-cold saline and weighed. The $\mathrm{pH}$ in the caecum content near the colon outlet was determined using a microelectrode (Knick, Portamess 751 calimatic pH meter, Berlin, Germany) equipped with a Hamilton biotrode (Reno, NV, USA). Caecum was opened and approximately $0.5 \mathrm{~g}$ of the content from the same area was sampled and stored at $-80^{\circ} \mathrm{C}$ until analysis for $\beta$-glucosidase (BGL) and $\beta$-glucuronidase (GUS) activity. Of the remaining content, one part (approximately $0 \cdot 1 \mathrm{~g}$ ) was suspended in nine parts of alkaline buffer $(0.1 \mathrm{M}$ Tris, $\mathrm{pH} 9 \cdot 6$, and $5 \mathrm{mg} / \mathrm{ml}$ malonic acid), centrifuged $\left(14000 \mathrm{~g}, 10 \mathrm{~min}, 4^{\circ} \mathrm{C}\right)$ and filtrated using a sterile $0.2 \mu \mathrm{m}$ filter. Samples were kept at $-80^{\circ} \mathrm{C}$ until analysis for SCFA. The caecum was rinsed in $0.9 \% \mathrm{NaCl}$ and weighed again empty. After the measurement of $\mathrm{pH}$, samples of caecal contents were taken and treated as described later. The caecum was weighed again empty. One millilitre of blood was collected into a PAXgene blood RNA tube for purification of RNA from the leucocytes (BD Denmark A/S, Brøndby, Denmark). The rest of the blood was collected in vacutainer tubes with heparin as anticoagulant. After $10 \mathrm{~min}$ of incubation on ice, samples were centrifuged at $1500 \mathrm{~g}$ for $10 \mathrm{~min}$ at $4^{\circ} \mathrm{C}$. Plasma was removed for later analysis. The leucocytes were carefully aspirated into $10 \%$ dimethyl sulphoxide in Histopaque-1077 (1:2) for comet analysis. The erythrocyte fraction was haemolysed by adding an equal volume of icecold water. All collected fractions were immediately frozen at $-80^{\circ} \mathrm{C}$.

\section{$H b$ and antioxidant enzymes}

On the day of analysis, the $50 \%$ haemolysates were thawed slowly on ice and diluted $2.5 \times$ in water and sonicated $10 \mathrm{~s}$ on ice. For the analysis of $\mathrm{Hb}$, glutathione reductase (GR; $E C$ 1.8.1.7) and catalase (EC 1.11.1.6), the samples were further diluted to $40 \times$ in $100 \mathrm{mM} \mathrm{KH}_{2} \mathrm{PO}_{4}$ buffer $(\mathrm{pH} \mathrm{7.4)}$ containing $1 \mathrm{~mm}$ dithiothreitol and $1 \mathrm{~mm}$ EDTA. Glutathione peroxidase (GPx1; EC 1.11.1.9) was analysed in $400 \times$ diluted samples. The $30 \mathrm{mg}$ liver powder was homogenised in $1 \mathrm{ml} \mathrm{PBS} \mathrm{pH} 7.4$ for $20 \mathrm{~s}$, and centrifuged at $10000 \mathrm{~g}$ for $20 \mathrm{~min}$ at $4^{\circ} \mathrm{C}$. The supernatant was used for measuring GR and GPx1 activities, together with total protein in $200 \times$ diluted samples.

Table 1. Composition of animal diets

\begin{tabular}{lcccc}
\hline Ingredient (g/kg feed) & Control (g) & Onion by-product $(\mathrm{g})$ & Onion extract $(\mathrm{g})$ & Onion residue $(\mathrm{g})$ \\
\hline Onion by-product & & 100 & 70 & \\
Onion extract & & & & 30 \\
Onion residue & 200 & 200 & 200 & 200 \\
Protein (casein) & 100 & 100 & 100 & 100 \\
Sucrose & 456 & 384 & 386 & 454 \\
Maize starch & 50 & 50 & 50 & 50 \\
Soya oil with AEDK vitamins & 20 & 20 & 20 & 80 \\
Soya oil & 80 & 80 & 80 & 32 \\
Maize oil & 32 & 32 & 32 & 12 \\
Mineral mixture* & 12 & 12 & 12 & 22 \\
B-Vitamin mixture† & 50 & 22 & 50 & 20 \\
Cellulose powder & 50 & &
\end{tabular}

*Containing in mg/kg diet: $3000 \mathrm{Ca} ; 1900 \mathrm{P} ; 3600 \mathrm{~K} ; 300 \mathrm{~S} ; 2500 \mathrm{Na} ; 1500 \mathrm{Cl} ; 600 \mathrm{Mg} ; 34 \mathrm{Fe} ; 30 \mathrm{Zn} ; 10 \mathrm{Mn} ; 0.20$ iodine; $0.15 \mathrm{Mo}$ $0.15 \mathrm{Se} ; 2.5 \mathrm{Si} ; 1.0 \mathrm{Cr} ; 1.0 \mathrm{~F} ; 0.5 \mathrm{Ni} ; 0.5 \mathrm{~B} ; 0.1 \mathrm{Li} ; 0.1 \mathrm{~V} ; 0.07 \mathrm{Co}$.

†Composition in mg/kg: 5000 (IU) vitamin A; 1000 (IU) vitamin $D_{3} ; 50$ (IU) vitamin E; 5 thiamine; 6 riboflavin; 8 pyridoxol; 2 folic acid; 0.3 D-biotin; 0.03 vitamin $B_{12} ; 20$ pantothenate; 2600 cholinhydrogentartrat; 400 inositol; 40 nicotinic acid; 1 phylloquinine; 40 p-aminobenzoic acid; 1000 methionine; 2000 L-cystine. 
The enzyme activities of GR, GPx1 and catalase, including $\mathrm{Hb}$ and total protein, were determined spectrophotometrically on an Automated Roche/Hitachi 912 Analyzer (Roche Diagnostic A/S, Hvidovre, Denmark) at $37^{\circ} \mathrm{C}$. The activity of GR was measured by following the consumption of NADPH at $340 \mathrm{~nm}$ by the method of Goldberg \& Spooner ${ }^{(29)}$. The GPx1 activity was determined by the coupled enzyme method described by Paglia \& Valentine ${ }^{(30)}$. The peroxidative activity of catalase was measured by the reaction of formaldehyde (HCHO) as described earlier elsewhere ${ }^{(31)}$.

\section{RNA isolation and quantitative real-time PCR}

Total RNA was isolated from $30 \mathrm{mg}$ liver powder using Qiagen RNeasy Mini kit according to the protocol described by the manufacturer (Qiagen, Hilden, Germany). Reverse transcriptase reactions were performed using Random Hexamer and SuperScript II Reverse Transcriptase kit according to the manufacturer's instructions (Invitrogen, Carlsbad, CA, USA). Relative mRNA expression was quantified by Real-time PCR on an ABI $7900 \mathrm{HT}$ FAST System using the comparative $\Delta \mathrm{Ct}$ method according to ABI manual (TaqMan Gene Expression Master Mix Protocol, Applied Biosystems, Foster City, CA, USA). PCR amplification for each gene target was performed in triplicate with cDNA samples equivalent to 3 ng RNA. The eukaryotic $18 \mathrm{~S}$ rRNA was used as an internal normalisation standard and data were expressed as fold difference in gene expression relative to a calibrator. Control group samples were pooled and used as a calibrant. TaqMan Gene Expression Assays used were the following: eukaryotic $18 \mathrm{~S}$ rRNA endogenous control (catalogue number 4352930E); rat Alas1 (catalogue number Rn00675323_g1); rat Cat (catalogue number Rn00680386_m1); rat Gclc (catalogue number Rn00689048_m1); rat Gpx1 (catalogue number Rn00577994_g1); rat $G r$ (catalogue number Rn01482160_m1); rat Nqo1 (catalogue number Rn00566528_m1).

\section{Comet assay}

The single-cell gel electrophoresis (Comet assay) was performed according to the recommendations of Tice et al. ${ }^{(32)}$, with some minor modifications. Observations were made at magnification of $400 \times$ with a fluorescent microscope (Leica microsystems A/S, Herlev, Denmark) coupled via a CCD camera to an imagine analysis system (Kinetic Imaging 5.0, Bromborough, UK). The data were based on 100 randomly selected cells per sample, fifty cells per each of the two replicate slides. Positive and negative controls were included for each assay. The Caco- 2 colon cancer cell line was used as negative control, and for positive control Caco- 2 cells were exposed to $4 \%$ of ethyl methanesulphonate in water. DNA damage was measured with the parameters of tail length, olive tail moment, tail extent moment and percentage tail DNA.

\section{$\beta$-Glucosidase and $\beta$-glucuronidase enzymes}

Samples of caecal content $(0 \cdot 2 \mathrm{~g})$ were homogenised in $1 \mathrm{ml}$ PBS, $0 \cdot 1 \% \mathrm{NaN}_{3} \mathrm{pH} 7 \cdot 4$, centrifuged at $10000 \mathrm{~g}$ for $20 \mathrm{~min}$ at $4^{\circ} \mathrm{C}$. The supernatant was used to determine the activity of bacterial BGL and GUS on an Automated Roche/Hitachi
912 Analyzer (Roche Diagnostic GmbH, Mannheim, Germany) at $37^{\circ} \mathrm{C}$.

BGL (EC 3.2.1.21) was assayed by determining the rate of hydrolysis of the substrate $p$-nitrophenyl- $\beta$-D-glucopyranoside. The amount of $p$-nitrophenol released was measured at $415 \mathrm{~nm}$. $p$-Nitrophenol was used as standard. GUS (EC 3.2.1.31) was measured by determining the rate of release of phenolphthalein from phenolphthalein- $\beta$-D-glucuronide at $540 \mathrm{~nm}$ with phenolphthalein as standard. The specific activity is defined as $\mathrm{U} / \mathrm{g}$ caecal content.

\section{SCFA in caecal content}

Propionic and butyric acids in caecal contents were analysed using capillary electrophoresis with indirect UV detection as described previously ${ }^{(33)}$.

\section{Statistical analysis}

The data were analysed for normal distribution using the Shapiro-Wilks' $W$ test and for homogeneity of variance using Levene's test $(P>0 \cdot 05)$. Some data had to be log-transformed in order to meet these criteria. The normally distributed and variance homogenous data were analysed by ANOVA. If significant differences were found between groups, further comparisons were done using least-square means. Other data were analysed using the non-parametric Wilcoxon rank-sums test. We used the Statistical Analysis Systems statistical package v. 9.1 (SAS Institute, Cary, NC, USA) and consider a $P$-value below 0.05 significant.

\section{Results}

\section{Onion powder and extracts}

The contents of sugars, fructans and quercetin were determined in the onion powder and its fractions in order to determine the exposures in the different rat groups. Table 2 shows the measured contents in each of the fractions. Recovery of sugars after extraction was $96.3 \%$ and recovery of quercetin was $105.6 \%$, whereas the apparent recovery of fructans was $156 \%$, indicating that extraction of fructans from the solid onion by-product was more efficient in the preparatory procedure than in the subsequent procedure used for quantitative analysis. A semiquantitative size distribution analysis of the fructans in the extract indicated that more than $90 \%$ had ten fructose residues or less and more than $60 \%$ had five residues or less. Very small amounts of longer chain fructans were present, very unlike the pattern seen for a reference chicory extract (data not shown). The quercetin was analysed before and after hydrolysis of glycosides, and $25-30 \%$ of the quercetin was present as the aglycone in each fraction (data not shown). Starch was not found in any of the samples (data not shown). The results of these analyses show that as a percentage of the total recovered materials, an amount corresponding to $85 \%$ of the sugars, $88 \%$ of the fructans and $91 \%$ of the flavonoid in the feed containing onion by-product was found in the feed with extract and the remaining $9-15 \%$ in the feed with residue. 
Table 2. Contents $(\mathrm{mg} / \mathrm{g})$ of sugars, fructans, quercetin and total $D M$ in the onion by-product and its fractions (Mean values and standard deviations)

\begin{tabular}{|c|c|c|c|c|c|c|c|c|c|c|c|c|}
\hline \multirow[b]{2}{*}{ Fraction } & \multicolumn{2}{|c|}{ Glucose } & \multicolumn{2}{|c|}{ Fructose } & \multicolumn{2}{|c|}{ Sucrose } & \multicolumn{2}{|c|}{ Fructans } & \multicolumn{2}{|c|}{ Quercetin } & \multicolumn{2}{|c|}{ Other DM } \\
\hline & Mean & SD & Mean & SD & Mean & SD & Mean & SD & Mean & SD & Mean & SD \\
\hline Onion by-product & $205 \cdot 6$ & 4.9 & 189.4 & $9 \cdot 2$ & 96.9 & 4.4 & 42.5 & 4.8 & 3.37 & 0.52 & 264 & 8 \\
\hline Onion extract & 215.8 & 4.8 & $199 \cdot 3$ & $5 \cdot 6$ & 85.7 & $2 \cdot 1$ & $71 \cdot 7$ & 8.8 & 3.97 & 0.01 & $315^{*}$ & 3 \\
\hline Onion residue & $102 \cdot 8$ & 8.6 & 95.5 & $8 \cdot 6$ & $53 \cdot 2$ & 3.9 & $30 \cdot 8$ & 2.9 & $1 \cdot 22$ & 0.33 & 643 & 2 \\
\hline
\end{tabular}

*Estimated on the basis of measured water content in this fraction.

\section{$\mathrm{Hb}$ and antioxidant enzymes}

The concentration of $\mathrm{Hb}$ expressed as $\mathrm{g} / \mathrm{l}$ of erythrocytes is shown in Fig. 1. There was a significant decrease $(P<0.05)$ in the $\mathrm{Hb}$ concentration in the rats fed with the three onion products compared with the rats in the control group. Antioxidant enzyme activities were measured in erythrocytes and in liver. There was a significant increase $(P<0 \cdot 05)$ in GR and GPx1 activities in erythrocytes of rats fed with the onion extract rich in FOS. In contrast, hepatic GPx1 activity was significantly decreased $(P<0.01)$ in the onion extract fed rats, but not in the other onion groups compared with the control group. Hepatic GR was not affected by any of the three onion products (Table 3).

\section{Gene expression of phase 2 enzymes and haeme synthesis}

The relative expression quantification method was used for gene expression quantification. The eukaryotic 18S rRNA was used as endogenous reference and data were expressed as fold difference in gene expression relative to a calibrant. Control group samples were pooled and used as calibrant. Rat $\beta$-actin was also used as endogenous reference, but gave the same results as obtained with eukaryotic 18S rRNA (not shown).

Hepatic gene expression revealed that Gr, Gpxl and Cat were not affected in onion fed rats. The gene expression of the phase 2 enzyme Gclc involved in glutathione (GSH) synthesis was significantly upregulated by a factor of more than 2 , but only in the rats given the onion residue. The expression of Nqol, which is also a phase 2 enzyme, was numerically increased to the same extent in this fraction, but the increase was not significant $(P=0 \cdot 14)$. We also explored

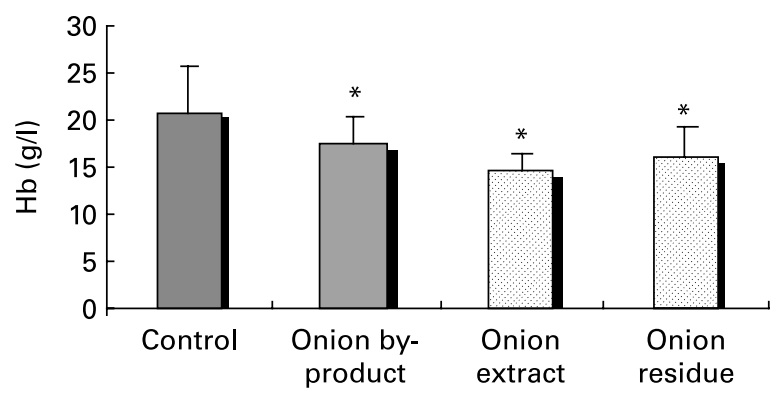

Fig. 1. $\mathrm{Hb}$ concentration of rats fed with an onion by-product and two derived onion fractions. Values are means of eight measurements performed in each rat group, with standard deviation depicted by vertical bars. * Significant difference between the onion groups and the control group at $P<0.05$. whether hepatic haeme biosynthesis was affected by measuring the gene expression of Alasl, the rate-limiting step in porphyrin biosynthesis. Feeding onion by-product powder or any of the two onion fractions had no significant effect on expression of this gene (Table 4).

\section{DNA damage}

Liver and leucocytes samples were used to measure DNA damage by the comet assay. At least 100 scores per sample were analysed, two samples from each animal were used. Internal positive and negative controls were included in each assay performed. Their values were within the laboratory historical control range. There were no significant differences $(P>0.05)$ in any of the comet parameters analysed between the control and the three onion groups in liver and leucocyte samples (data not shown).

\section{Caecum weight, $\mathrm{pH}$ and transit time}

Data on animal caecal weights, caecal $\mathrm{pH}$ and transit time values are reported in Table 5. The caecal weight of rats fed with onion by-product was not significantly higher $(P=0 \cdot 12)$ compared to the control group and the two onion fractions groups. Caecal $\mathrm{pH}$ was significantly decreased by the onion by-product and both fractions $(P<0 \cdot 01)$. No significant difference $(P>0.05)$ was found when gastrointestinal transit time was measured in the three onion groups compared to the control group.

\section{Bacterial activities}

BGL and GUS activities were measured in the caecal contents (Fig. 2). Both activities were significantly increased $(P<0 \cdot 05)$ in the three onion groups compared with the control group.

\section{SCFA}

There was a significant increase $(P<0.05)$ in the formation of caecal propionate and butyrate in all onion fed rats (Fig. 3). The effect was significantly stronger in the onion residue fed group compared with the onion by-product and the onion extract fed groups.

\section{Discussion}

In the present study, we have investigated the biological responses of healthy rats fed with an onion by-product and two derived fractions. The onion powder was obtained from 
Table 3. Effect of an onion by-product and two derived onion fractions on rat erythrocytes and hepatic antioxidant enzyme activities

(Mean values and standard deviations, $n 8$ )

\begin{tabular}{|c|c|c|c|c|c|c|c|c|c|c|}
\hline \multirow[b]{3}{*}{ Group } & \multicolumn{6}{|c|}{ Erythrocytes } & \multicolumn{4}{|c|}{ Liver } \\
\hline & \multicolumn{2}{|c|}{ GR (U/g Hb) } & \multicolumn{2}{|c|}{$\begin{array}{c}\text { GPx1 } \\
(\mathrm{U} / \mathrm{g} \mathrm{Hb})\end{array}$} & \multicolumn{2}{|c|}{ CAT (U/g Hb) } & \multicolumn{2}{|c|}{$\begin{array}{l}\mathrm{GR}(\mathrm{U} / \mathrm{mg} \\
\text { protein) }\end{array}$} & \multicolumn{2}{|c|}{$\begin{array}{l}\mathrm{GPx} 1(\mathrm{U} / \mathrm{mg} \\
\text { protein) }\end{array}$} \\
\hline & Mean & SD & Mean & SD & Mean & SD & Mean & SD & Mean & SD \\
\hline Control & 1.9 & 0.5 & 1521 & 182 & 130 & 12 & 70 & 17 & 2013 & 408 \\
\hline Onion by-product & 1.7 & 0.2 & 1507 & 192 & 124 & 32 & 78 & 24 & 1770 & 498 \\
\hline Onion extract & $2 \cdot 3^{*}$ & 0.3 & $1810^{*}$ & 127 & 153 & 25 & 69 & 9 & $1470^{\star *}$ & 225 \\
\hline Onion residue & 1.9 & 0.2 & 1677 & 252 & 147 & 25 & 70 & 23 & 1832 & 522 \\
\hline
\end{tabular}

GR, glutathione reductase; GPx1, glutathione peroxidase; CAT, catalase.

Mean values were significantly different from those of the control group: ${ }^{\star} P<0.05,{ }^{\star \star} P<0.01$.

a pasteurised 'Recas' paste, which was chosen among a battery of stabilised onion by-products (juices, bagasses and pastes) from different cultivars. From a technological and nutritional point of view, stabilised onion by-products from the 'Recas' cultivar showed good characteristics to be developed as antioxidant food ingredients. Pasteurisation applied as stabilisation treatment and paste as a form of onion by-product kept the bioactive and technological characteristics of fresh onion. The by-product chosen in the previous study showed several advantages: a remarkable antioxidant activity; a high content of polyphenols; an excellent antibrowning effect ${ }^{(6)}$.

We extracted the soluble fibre from this onion by-product powder in order to elucidate whether fructans and FOS are partly responsible for the potential health-promoting effects of onion. Our analyses show that a very large part of the water or ethanol soluble compounds, including sugars, FOS and flavonoids were successfully extracted into this fraction. For FOS, we succeeded mainly in extracting shorter chain length fructans including kestose. It is possible that some longer chain FOS remained in the residue fraction obtained after extraction, but onion is known to be mainly composed of short chain FOS, so we find this unlikely. The residue fraction seems therefore to be mostly composed of insoluble cell wall material. Quercetin was used as a marker for ethanol soluble onion compounds, and also these compounds were only left in small amounts in the residue. We have no direct data on the concentration of OSC in the fractions; but in a different study, we have analysed the urine from these rats by NMR and observed that organosulphur metabolites were distributed between the extract and the residue groups according to the fractions of onion materials in their diets $(7: 3$, data to be published elsewhere), indicating that the doses to the rats in the three groups would be approximately 3:2:1 for onion by-product, extract and residue, respectively.

A significant decrease in the $\mathrm{Hb}$ concentration of the rats fed with onion compared with rats in the control group was a main finding (Fig. 1). In agreement with the present results, several studies using different animals as models concluded that onion supplementation resulted in dose-dependent reductions in erythrocyte counts and $\mathrm{Hb}$ levels involving oxidative damage to erythrocytes and consequent haemolytic anaemia and Heinz body formation ${ }^{(34,35)}$. As far as we are aware, a similar response has not been described in human subjects, indicating that this toxic effect is not present or at least much weaker in human subjects. Onion OSC have been proposed to be responsible of this toxic effect in rats due to their ability to generate reactive oxygen species in the presence of GSH. Particularly, the relatively lipophilic dipropyl tri- and tetrasulphides and dipropenyl disulphide may be largely responsible for the onion toxicity observed in some animals ${ }^{(36,37)}$. This would be in accordance with our observation that the residue was also toxic, so hot ethanol was not sufficient for full extraction of OSC.

With respect to onion antioxidant properties, several rat studies have related these properties with the onion antihyperglycaemic or antihypertensive effects ${ }^{(35,38)}$. Some recent studies have described an enhancement of the total antioxidant capacity of plasma in rats fed with onions ${ }^{(39,40)}$. We found that antioxidant enzyme activities in erythrocytes showed

Table 4. Effect of an onion by-product and two derived fractions on rat hepatic gene expression of antioxidant enzymes†

(Mean values and standard deviations, $n 5$ )

\begin{tabular}{|c|c|c|c|c|c|c|c|c|c|c|c|c|}
\hline \multirow[b]{2}{*}{ Group } & \multicolumn{2}{|c|}{$G r$} & \multicolumn{2}{|c|}{ Gpx1 } & \multicolumn{2}{|c|}{ Cat } & \multicolumn{2}{|c|}{ Gclc } & \multicolumn{2}{|c|}{ Nqo1 } & \multicolumn{2}{|c|}{ Alas1 } \\
\hline & Mean & SD & Mean & SD & Mean & SD & Mean & SD & Mean & SD & Mean & SD \\
\hline Control & 0.73 & 0.27 & 0.80 & 0.30 & 0.95 & 0.36 & 0.76 & 0.42 & 0.79 & 0.25 & 0.82 & 0.17 \\
\hline Onion by-product & 0.72 & 0.38 & 0.73 & 0.29 & 0.88 & 0.57 & 0.90 & 0.44 & 0.97 & 0.24 & 0.67 & 0.53 \\
\hline Onion extract & 0.83 & 0.40 & $1 \cdot 13$ & 0.47 & 0.87 & 0.40 & 1.02 & 0.38 & 0.91 & 0.32 & 0.52 & 0.22 \\
\hline Onion residue & 1.06 & $1 \cdot 16$ & 1.27 & 0.82 & 0.76 & 0.54 & $2 \cdot 12^{\star}$ & 1.59 & $2 \cdot 11$ & $2 \cdot 32$ & 0.70 & 0.45 \\
\hline
\end{tabular}

Gr, glutathione reductase; Gpx1, glutathione peroxidase; Cat catalase. Phase 2 enzymes: Gclc, $\gamma$-glutamate cysteine ligase catalytic subunit; Nqo1, NAD(P)H: quinone oxidoreductase; Alas1, 5-aminolevulinate synthase.

Mean value was significantly different from those of the control group: ${ }^{*} P<0.05$.

$\dagger$ Gene expression of target genes is related to the endogenous reference $18 \mathrm{~S}$ rRNA and to a calibrant (relative expression quantification). 
Table 5. Caecal weight, caecal $\mathrm{pH}$ and transit time in rats fed with an onion by-product and two derived onion fractions

(Mean values and standard deviations, $n 8$ )

\begin{tabular}{|c|c|c|c|c|c|c|}
\hline \multirow[b]{2}{*}{ Group } & \multicolumn{2}{|c|}{$\begin{array}{c}\text { Caecal } \\
\text { weight }(\mathrm{g})\end{array}$} & \multicolumn{2}{|c|}{ Caecal pH } & \multicolumn{2}{|c|}{$\begin{array}{l}\text { Transit time } \\
\text { (min) }\end{array}$} \\
\hline & Mean & SD & Mean & SD & Mean & SD \\
\hline Control & $2 \cdot 2$ & 0.5 & $7 \cdot 0$ & 0.1 & 609 & 56 \\
\hline Onion by-product & 3.0 & $1 \cdot 1$ & $6 \cdot 7^{\star}$ & 0.1 & 606 & 95 \\
\hline Onion extract & $2 \cdot 2$ & 0.4 & $6 \cdot 7^{\star}$ & 0.1 & 577 & 102 \\
\hline Onion residue & $2 \cdot 1$ & 0.9 & $6 \cdot 6^{*}$ & 0.1 & 636 & 87 \\
\hline
\end{tabular}

Mean value was significantly different from those of the control group: ${ }^{\star} P<0.01$.

a significant increase in GR and GPx1 activities when rats were fed with the onion extract rich in FOS (Table 3). This effect might be a result of erythrocyte GSH depletion leading to an increased demand for GSH-dependent enzymes and especially for reduced GSH. In agreement with this assumption, the hepatic gene expression of Gclc was higher after feeding with onion fractions (Table 4), but only significantly so in the residue fraction. GPx1 activity in liver tissue of rats fed with the onion extract was significantly decreased compared with the activities found in the rest of the groups (Table 3). We speculate that the antioxidant flavonols, quercetin and its glycosides may have acted as inhibitors.

Onions have also been proposed to be chemoprotective due to the ability of their OSC to increase activities of phase 2 detoxification enzymes and proteins, including GSH $S$-transferase, epoxide hydrolase, NAD(P)H:quinone oxidoreductase 1 and UDP-glucuronosyltransferase ${ }^{(41,42)}$. Moreover, the combination of OSC and the glycosides of quercetin found in onions have been reported to exert chemoprotective action by enhancing the phase 2 enzymes and inhibiting phase 1 enzyme activities such as cytochromes P450. It has been shown by others that consumption of onion decreased the activity of CYP2E1 ${ }^{(43)}$.

Hepatic gene expression evaluated in the present study revealed an upregulation of the phase 2 enzyme Gclc in rats fed with the onion residue fraction, but not in rats fed with the onion by-product or the onion extract fraction giving higher doses of OSC. By contrast, none of the other antioxidant and phase 2 genes evaluated in the present study was significantly up- or downregulated by onion supplementation, although the expression of $\mathrm{Nqol}$ apparently increased

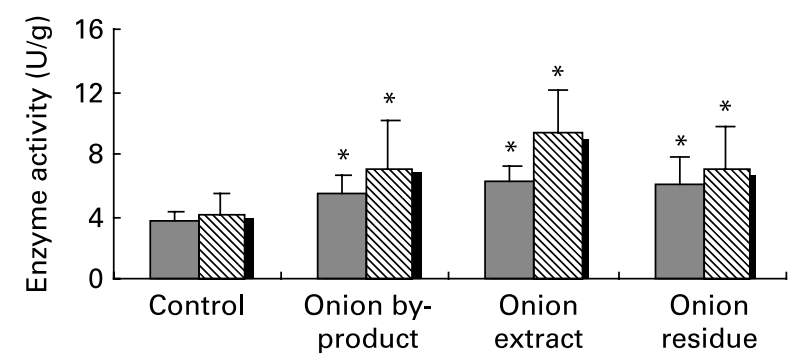

Fig. 2. Effect of an onion by-product and two derived onion fractions on bacterial $\beta$-glucosidase ( $\square$, BGL) and $\beta$-glucuronidase ( $\mathbb{}$, GUS) activities in caecal content. Values are means of eight measurements performed in each rat group, with standard deviation depicted by vertical bars. * Significant difference between the onion groups and the control group at $P<0.05$.

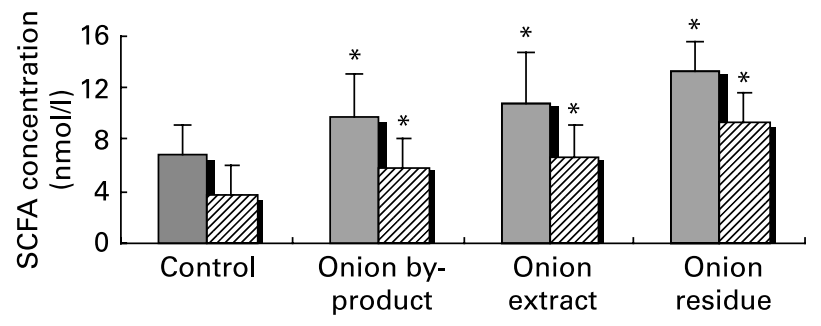

Fig. 3. Effect of an onion by-product and two derived onion fractions on SCFA content: propionic $(\square)$ and butyric $(\mathbb{Z})$ acids in caecum. Values are means of eight measurements performed in each rat group, with standard deviation depicted by vertical bars. * Significant difference between the onion groups and the control group at $P<0.05$.

with a pattern similar to that of Gclc (Table 4). If the OSC compounds are responsible for Gclc induction, our data indicate that the more lipophilic OSC may be the more efficient enzyme inducers since only the residue fraction was significantly active. Expression of hepatic Alas 1 did not follow these same patters and was unaffected by feeding rats with onion products, indicating that toxicity is not due to global downregulation of haeme biosynthesis. On the other hand, upregulation to compensate for haeme loss does not take place in the liver, but may happen in the red bone marrow. Additional studies with further fractionation will have to be performed in order to study which onion compounds with or without thiol groups in their composition play a role in onion toxicity or in modulating phase 2 enzyme activities.

Since GSH depletion might cause increased formation of reactive chemical species, including oxygen radicals, the potential genotoxicity of onion was also evaluated by performing the comet assay. Our results show that the onion products did not decrease the background level of DNA damage (data not shown). Therefore, it could be inferred that the three onion products were not genotoxic. Recent studies have indicated that OSC protect human-derived cells against oxidative DNA damage ${ }^{(44,45)}$. With the present study, it cannot be verified that these onion products possess an antigenotoxic effect.

We observed a significant lowering effect by feeding the onion by-product or either of the two onion fractions on rat caecal $\mathrm{pH}$ without an effect on transit time (Table 5). A marked effect was also shown on bacterial BGL and GUS activities (Fig. 2) and on gut fermentation to SCFA (Fig. 3).

BGL and GUS enzymes are the principal glycosidases produced by the intestinal microbiota, which hydrolyse glycosidic bonds in the gut originating either from the diet or from compounds excreted with the bile. As a result, there is a release of aglycones or metabolites some of which are potentially toxic or carcinogenic. The health significance of increases in BGL or GUS is uncertain. Interestingly, slightly higher BGL and GUS activities were found when rats were fed with the onion extract fraction compared with the other rat groups fed with onion by-product or the residue. A significant increase in caecal lactobacilli and bifidobacteria could partly explain the increase in the BGL activity due to the fact that these two colonic bacterial genera possess higher levels of BGL activities. However, the Bifidobacterium genus expresses a low GUS activity, and consequently other bacterial genera might be involved in the observed rise in GUS activity ${ }^{(46)}$. Moreover, in accordance with Lara-Villoslada et al. ${ }^{(47)}$, short-chain FOS with a high content of kestose promoted 
a more favourable intestinal microbiota increasing caecal lactobacilli and bifidobacteria counts as well as SCFA production in healthy rats. Thus, we expect similar results in the present study since we confirmed the findings of others of a high presence of this trisaccharide in the onion extract ${ }^{(23)}$.

SCFA are important products formed by fermentation of inulin-type fructans with rat or human gut microbiota. We observed increased levels of propionate and butyrate with all three products, including the group of rats fed with the low FOS onion residue (Fig. 3), indicating that the insoluble fibres contribute significantly to the fermentation. Butyrate has been shown to increase apoptosis in colon cell lines and to protect from genotoxic carcinogens by enhancing expression of genes involved in detoxification ${ }^{(48)}$. Our results, therefore, show that onion by-products possess additional fermentable fibres compared to FOS-rich additives. Decreased $\mathrm{pH}$ is often seen as a consequence of caecal fermentation, and we have previously found that decreased $\mathrm{pH}$ was the best predictor of subsequent lower risk of colon cancer in rats fed sugars, oligofructose and inulin ${ }^{(49)}$. Overall, these effects in the caecum would clearly indicate that increased fermentation of onion fibres is taking place, and that this has altered the functionality and possibly also the composition of the gut microbiota leading to a healthier phenotype.

\section{Conclusion}

The present study represents a first step assuring the safety of onion by-products as a food ingredient. Feeding rats with an onion by-product and two derived onion fractions did not involve any genotoxic risk despite our reproduction of the well-known effect of onion on anaemia in rodents. The soluble fraction of the onion by-product seems to affect in vivo antioxidant properties, whereas the residue fraction caused phase 2 induction. Moreover, the onion by-product and the two derived onion fractions exert prebiotic properties as evidenced by decreased $\mathrm{pH}$, increased butyrate production and altered gut microbiota enzyme activities. Additional model studies would have to be done with additional wellcharacterised subfractions in order to further explore these effects and to relate them with specific onion components. Human studies would be needed to ascertain that the effects are related to improved health.

\section{Acknowledgements}

The present study was supported by funding from the Spanish Ministry of Science and Innovation (AGL200309 138-C04-01; 200670I08; Consolider-Ingenio Programme 2010, FUN-C-FOOD, CSD2007-00 063; and AGL200804798-C02-01/ALI) and from the Danish Ministry of Food, Agriculture and Fisheries (NuBI, 3304-FVFP-060696-01). E. R.-M. wishes to thank the Spanish Ministry of Science and Innovation for a Predoctoral Fellowship. We thank Vibeke Kegel and Margit Wagtberg Hansen for their excellent technical assistance. The cooperation of Anis Arnous with the onion fractions' freeze-drying process is also gratefully appreciated. The author's responsibilities were as follows: E. R.-M., C. S.-M. and M. P. C. provided the onion by-product and produced the onion powder. C. S.-M. proposed the evaluation of onion by-product bioactivity, suggesting the collaboration between the groups. T. H. N. and T. B. analysed the products for contents of sugars, FOS and quercetin. L. O. D. planned the rat study. M. P. was responsible for the animal study protocol and diets. E. R.-M. was responsible for the onion by-product extraction into two fractions, comet assay and antioxidant enzymes' analyses. B. N. K. was responsible for gene expression, bacterial enzymes and antioxidant enzymes' analyses. M. L. B. supervised the comet assay performance and results' data. M. H. was responsible for the SCFA and rat caecal $\mathrm{pH}$; S. L. for the transit time measurement. L. O. D. provided statistical support. E. R.-M. wrote the first draft of the manuscript. L. O. D. and C. S.-M. helped E. R.-M. with the first manuscript draft. M. P. C., C. S. -M., and L. O. D. supervised E. R. -M. manuscript drafts. All authors approved the final manuscript. All authors declared that they had no conflict of interest.

\section{References}

1. Aggarwal BB \& Shishodia S (2006) Molecular targets of dietary agents for prevention and therapy of cancer. Biochem Pharmacol 71, 1397-1421.

2. Sengupta A, Ghosh S \& Bhattacharjee S (2004) Allium vegetables in cancer prevention: an overview. Asian Pac J Cancer Prev 5, 237-245.

3. Stajner D, Miliç N, Canadanoviç-Brunet J, et al. (2006) Exploring Allium species as a source of potential medicinal agents. Phytother Res 20, 581-584.

4. Slimestad R, Fossen T \& Vågen IM (2007) Onions: a source of unique dietary flavonoids. $J$ Agric Food Chem 55, 10067-10080.

5. Griffiths G, Trueman L, Crowther T, et al. (2002) Onions - a global benefit to health. Phytother Res 16, 603-615.

6. Roldán E, Sánchez-Moreno C, de Ancos B, et al. (2008) Characterisation of onion (Allium cepa L.) by-products as food ingredients with antioxidant and antibrowning properties. Food Chem 108, 907-916.

7. Corzo-Martínez M, Corzo N \& Villamiel M (2007) Biological properties of onions and garlic. Trends Food Sci Technol 18, 609-625.

8. Price KR \& Rhodes MJC (1997) Analysis of the major flavonol glycosides present in four varieties of onion (Allium cepa) and changes in composition resulting from autolysis. J Sci Food Agric 74, 331-339.

9. Boyle SP, Dobson VL, Duthie SJ, et al. (2000) Absorption and DNA protective effects of flavonoid glycosides from an onion meal. Eur J Nutr 39, 213-223.

10. Femia AP, Caderni G, Ianni M, et al. (2003) Effect of diets fortified with tomatoes or onions with variable quercetin-glycoside content on azoxymethane-induced aberrant crypt foci in the colon of rats. Eur J Nutr 42, 346-352.

11. Taché S, Ladam A \& Corpet DE (2007) Chemoprevention of aberrant crypt foci in the colon of rats by dietary onion. Eur $J$ Cancer 43, 454-458.

12. Nemeth K \& Piskula MK (2007) Food content, processing, absorption and metabolism of onion flavonoids. Crit Rev Food Sci Nutr 47, 397-409.

13. Bianchini F \& Vainio H (2001) Allium vegetables and organosulfur compounds: do they help prevent cancer? Environ Health Perspect 109, 893-902.

14. Lanzotti V (2006) The analysis of onion and garlic. J Chromatogr A 1112, 3-22. 
15. Stan SD, Kar S, Stoner GD, et al. (2008) Bioactive food components and cancer risk reduction. J Cell Biochem 104, 339-356

16. Jaime L, Martín-Cabrejas MA, Mollá E, et al. (2001) Effect of storage on fructan and fructooligosaccharide of onion (Allium cepa L.). J Agric Food Chem 49, 982-988.

17. Jaime L, Mollá E, Fernández A, et al. (2002) Structural carbohydrate differences and potential source of dietary fiber of onion (Allium cepa L.) tissues. J Agric Food Chem 50, 122-128.

18. Kaack K, Christensen LP, Hansen SL, et al. (2004) Nonstructural carbohydrates in processed soft fried onion (Allium cepa L.). Eur Food Res Technol 218, 372-379.

19. Shiomi N, Benkeblia N \& Onodera S (2005) The metabolism of the fructo-oligosaccharides in onion bulbs: a comprehensive review. J Appl Glycosci 52, 121-1277.

20. Pool-Zobel BL (2005) Inulin-type fructans and reduction in colon cancer risk: review of experimental and human data. Br J Nutr 93, S73-S90.

21. Benkeblia N \& Shiomi N (2006) Hydrolysis kinetic parameters of DP 6, 7, 8, and 9-12 fructooligosaccharides (FOS) of onion bulb tissues. Effect of temperature and storage time. J Agric Food Chem 54, 2587-2592.

22. Mabel MJ, Sangeetha PT, Platel K, et al. (2008) Physicochemical characterization of fructooligosaccharides and evaluation of their suitability as a potential sweetener for diabetics. Carbohydr Res 343, 56-66.

23. Jaime L, Martínez F, Martín-Cabrejas MA, et al. (2001) Study of total fructan and fructooligosaccharide content in different onion tissues. J Sci Food Agric 81, 177-182.

24. Beutler HO (1984) Monosaccharides and derivatives. D-Fructose. In Methods of Enzymatic Analysis, vol. 6, pp. 321-327 [HU Bergmeyer, editor]. Weinheim: Verlag Chemie.

25. Kunst A, Draeger B \& Ziegenhorn J (1984) Monosaccharides and derivatives. D-Glucose. In Methods of Enzymatic Analysis, vol. 6, pp. 163-172 [HU Bergmeyer, editor]. Weinheim: Verlag Chemie.

26. Outlaw WH \& Tarczynski MC (1984) Poly-, oligo- and disaccarides. Sucrose. In Methods of Enzymatic Analysis, vol. 6, pp. 96-103 [HU Bergmeyer, editor]. Weinheim: Verlag Chemie.

27. Nielsen TH, Skjærbæk HC \& Karlsen P (1991) Carbohydrate metabolism during fruit development in sweet pepper (Capsicum annuum L.) plants. Physiol Plantarum 82, 311-319.

28. Blennow A, Bay-Smidt AM, Olsen CE, et al. (1998) The degree of starch phosphorylation is related to the chain length distribution of the neutral and the phosphorylated chains of amylopectin. Carbohydr Res 307, 45-54.

29. Goldberg DM \& Spooner RJ (1983) Assay of glutathione reductase. In Methods in Enzymology, vol. 3, pp. 258-265 [HU Bergmayer, editor]. New York: Academic Press.

30. Paglia DE \& Valentine WN (1967) Studies on the quantitative and qualitative characterization of erythrocyte glutathione peroxidase. J Lab Clin Med 70, 158-169.

31. Johansson LH \& Borg HLA (1988) A spectrophotometric method for determination of catalase activity in small tissue samples. Anal Biochem 174, 331-336.

32. Tice RR, Agurell E, Anderson D, et al. (2000) Single cell gel/ comet assay: guidelines for in vitro and in vivo genetic toxicology testing. Environ Mol Mutagen 35, 206-221.

33. Hansen M, Baunsgaard D, Autrup H, et al. (2008) Sucrose, glucose and fructose have similar genotoxicity in the rat colon and affect the metabolome. Food Chem Toxicol 46, 752-760.
34. Ostrowska E, Gabler NK, Sterling SJ, et al. (2004) Consumption of brown onions (Allium cepa var. cavalier and var. density) moderately modulates blood lipids, haematological and haemostatic variables in healthy pigs. Br J Nutr 91, 211-218.

35. Yamamoto Y, Aoyama S, Hamaguchi N, et al. (2005) Antioxidative and antihypertensive effects of Welsh onion on rats fed with a high-fat high-sucrose diet. Biosci Biotechnol Biochem 69, $1311-1317$

36. Yamato O, Hayashi M, Kasai E, et al. (1999) Reduced glutathione accelerates the oxidative damage produced by sodium n-propylthiosulfate, one of the causative agents of onioninduced hemolytic anemia in dogs. Biochim Biophys Acta 1427, 175-182.

37. Munday R, Munday JS \& Munday CM (2003) Comparative effects of mono-, di-, tri-, and tetrasulfides derived from plants of the Allium family: redox cycling in vitro and hemolytic activity and phase II enzyme induction in vivo. Free Radic Biol Med 34, 1200-1211.

38. El-Demerdash FM, Yousef MI \& El-Naga NIA (2005) Biochemical study on the hypoglycemic effects of onion and garlic in alloxan-induced diabetic rats. Food Chem Toxicol $43,57-63$.

39. Son Y, Jung W-K, Jeon Y-J, et al. (2008) Protective effects of fermented onion juice containing higher amount of querectin aglycone against oxidative stress by $2,2^{\prime}$-azobis (2-amidinopropane) dihydrochloride (AAPH) treatment in Sprague-Dawley rats. Eur Food Res Technol 226, 473-482.

40. Park J, Kim J \& Kim MK (2007) Onion flesh and onion peel enhance antioxidant status in aged rats. J Nutr Sci Vitaminol $\mathbf{5 3}, 21-29$.

41. Munday R, Munday CM, Helmut Sies, et al. (2004) Induction of phase II enzymes by aliphatic sulfides derived from garlic and onions: an overview. In Methods in Enzymology, pp. 449-456. New York: Academic Press.

42. Guyonnet D, Belloir C, Suschetet M, et al. (2001) Antimutagenic activity of organosulfur compounds from Allium is associated with phase II enzyme induction. Mutat Res Genet Toxicol Environ Mutagen 495, 135-145.

43. Teyssier C, Amiot MJ, Mondy N, et al. (2001) Effect of onion consumption by rats on hepatic drug-metabolizing enzymes. Food Chem Toxicol 39, 981-987.

44. Arranz N, Haza AI, García A, et al. (2007) Protective effects of organosulfur compounds towards N-nitrosamine-induced DNA damage in the single-cell gel electrophoresis (SCGE)/HepG2 assay. Food Chem Toxicol 45, 1662-1669.

45. Belloir C, Singh V, Daurat C, et al. (2006) Protective effects of garlic sulfur compounds against DNA damage induced by direct- and indirect-acting genotoxic agents in HepG2 cells. Food Chem Toxicol 44, 827-834.

46. De Preter V, Raemen H, Cloetens L, et al. (2008) Effect of dietary intervention with different pre- and probiotics on intestinal bacterial enzyme activities. Eur J Clin Nutr 62, 225-231.

47. Lara-Villoslada F, de Haro O, Camuesco D, et al. (2006) Shortchain fructooligosaccharides, in spite of being fermented in the upper part of the large intestine, have anti-inflammatory activity in the TNBS model of colitis. Eur J Nutr 45, 418-425.

48. Pool-Zobel BL \& Sauer J (2007) Overview of experimental data on reduction of colorectal cancer risk by inulin-type fructans. J Nutr 137, S2580-S2584.

49. Jacobsen H, Poulsen M, Dragsted LO, et al. (2006) Carbohydrate digestibility predicts colon carcinogenesis in azoxymethane treated rats. Nutr Cancer 55, 163-170. 